DOI: $10.1590 / 1089-6891 v 18 \mathrm{e}-41239$

ZOOTECNIA

\title{
PRODUTIVIDADE DO MILHETO EM TRÊS DENSIDADES DE SEMEADURA E DUAS ALTURAS DE CORTE
}

\section{PRODUCTIVITY OF PEARL MILLET THREE SOWING DENSITIES AND TWO CUTTING HEIGHTS}

\author{
Josilene da Silva Trindade ${ }^{1}$ \\ Edgar Alain Collao Saenz ${ }^{2}$ \\ Márcia Dias ${ }^{2}$ \\ Vera Lúcia Banys ${ }^{2}$ \\ Fernando Jose dos Santos Dias ${ }^{2}$ \\ Alyson Andrade Pinheiro ${ }^{2 *}$ \\ ${ }^{1}$ Faculdades Unidas do Vale do Araguaia, Barra do Garças, MT, Brasil. \\ 2Universidade Federal de Goiás - Regional de Jataí, Jataí, GO, Brasil. \\ *Autor para correspondência - jagualyson@bol.com.br
}

\section{Resumo}

Com o objetivo de avaliar a produção do milheto (Pennisetum glaucum (L.)) em diferentes densidades de semeadura e manejado em duas alturas de corte, foi realizado um experimento na Fazenda Experimental da Universidade Federal de Goiás, no período de março a julho (safrinha) após a colheita da soja. O delineamento experimental utilizado foi blocos ao acaso em arranjo

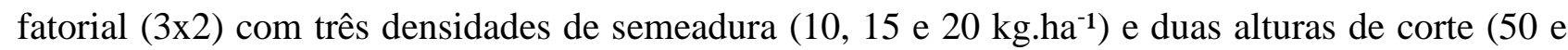
$70 \mathrm{~cm}$ ). Os dados foram analisados no programa SAS versão 9.2, considerando-se o efeito de densidade na parcela e altura na subparcela. As médias foram comparadas pelo teste Tukey a 5\% de probabilidade. A densidade de semeadura não influenciou $(\mathrm{P}<0,05)$ nas produções de massa verde e matéria seca (MS). O corte a $70 \mathrm{~cm}$ teve maior produção de MS por corte. Quando avaliada a produção total do período, não houve $(\mathrm{P}>0,05)$ influência da densidade de semeadura ou da altura de corte. Por não ter afetado a produção de MS e por permitir maior período de utilização da pastagem com menor gasto com sementes no plantio, recomenda-se a densidade de semeadura de $10 \mathrm{~kg} \cdot \mathrm{ha}^{-1}$ com corte do milheto aos $50 \mathrm{~cm}$ de altura.

Palavras-chave: estresse hídrico; manejo; safrinha.

\begin{abstract}
To evaluate the production of pearl millet (Pennisetum glaucum (L.)) at different sowing densities and managed under different cutting heights, a field trial was carried out in the experimental farm of Universidade Federal de Goiás, from March to July (off season crop) after the soybean harvest. A completely randomized block experimental design in a factorial arrangement $(3 \times 2)$ with three
\end{abstract}




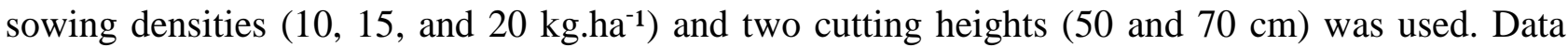
were analyzed with SAS ${ }^{\circledR} 9.2$ (SAS Institute Inc., Cary, NC), considering the density effect in the plot and the height in the subplot. Means were compared by Tukey test. The sowing density did not affect $(\mathrm{P}<0.05)$ green mass and dry matter $(\mathrm{DM})$ production. In the comparison between cutting height, the height of $70 \mathrm{~cm}$ had higher DM production. However, the total production of the period was not affected $(\mathrm{P}>0.05)$ by sowing density and height management. Total production per hectare was similar between densities and cutting heights. As the cutting height did not affect DM production and allowed a longer period of pasture utilization and lower deployment cost, we recommend a sowing density of $10 \mathrm{~kg} \cdot \mathrm{ha}^{-1}$ and millet cut at $50 \mathrm{~cm}$.

Keywords: management; off season crop; water stress.

Recebido em: 10 maio de 2016

Aceito em: 12 maio de 2017

\section{Introdução}

O Brasil Central apresenta sazonalidade na produção de forrageiras devido à variação climática observada nos períodos seco e chuvoso. Por este motivo, atenuar a escassez de alimento na época seca ainda é um desafio para a maioria dos produtores.

O milheto possui características favoráveis como cultura e adaptação aos solos do Cerrado, pois possui sistema radicular profundo e tolerância ao estresse hídrico ${ }^{(1)}$. Devido às suas características agronômicas de alta resistência à seca, adaptação aos solos de baixa fertilidade, crescimento rápido e boa produção de biomassa, esta cultura tem-se apresentado como uma das melhores opções para a cobertura do solo em áreas de semeadura direta no Brasil ${ }^{(2,3)}$.

Além disto, o milheto tem sido usado na alimentação animal como volumoso, tanto no pastejo direto como na produção de silagem ${ }^{(4)}$ e na produção de grãos usados na fabricação de ração animal $^{(5-7)}$. Portanto, vem se destacando como cultura de potencial para a implantação em sistemas de integração lavoura-pecuária.

No Sudoeste de Goiás, a utilização do milheto como pastagem é pequena, sendo seu uso destacado na formação de palhada para a cobertura do solo em sistema de plantio direto e, em menor escala, para a produção de grãos. Em função disso, objetivou-se com este trabalho avaliar a possibilidade do uso do milheto como forragem no Sudoeste de Goiás.

\section{Material e Métodos}

O experimento foi conduzido na Fazenda Escola Santa Rosa do Rochedo, na área experimental da Regional Jataí da Universidade Federal de Goiás - GO, localizada a $17^{\circ} 53^{\prime}$ de Latitude Sul, 5143' de Longitude Oeste e 670 metros de altitude em solo classificado como Latossolo Vermelho distroférrico com textura argilosa, segundo classificação da $\operatorname{EMBRAPA}^{(8)}$, e que recebeu como 
adubação pré-plantio o formulado NPK 4-20-18 na dosagem de 180 kg.ha-1 à lanço, conforme protocolo da fazenda.

A adubação de correção foi realizada no dia 05 de março e a semeadura do milheto aconteceu no dia 15 de março, no período da safrinha, após a colheita da cultura da soja, em sulco com distribuição manual de sementes em linhas com espaçamento de $45 \mathrm{~cm}$. Foram utilizadas sementes de milheto ADR500®, com VC de 74,18\%, conforme Teste de Tretazolium realizado pelo Laboratório do Centro Universitário de Mineiros - UNIFIMES.

Após 25 dias, foi feita análise do solo, que apresentou $\mathrm{pH}\left(\mathrm{H}_{2} \mathrm{O}\right)$ 5,69; P 5,82 mg/dm³; K 122,80 mg/dm³ Zn 2,97 mg/dm³; Fe 29,2 mg/dm³; Mn 38,8 mg/dm³; Cu 10,2 mg/dm³; Ca 3,23 Cmolc/dm;

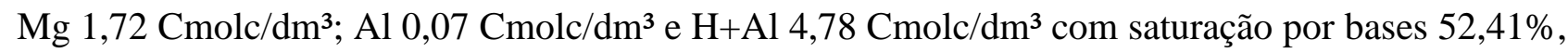
saturação por $\mathrm{Al} \mathrm{1,31 \%} \mathrm{e} \mathrm{matéria} \mathrm{orgânica} \mathrm{3,52 \% .}$

O clima da região segundo classificação de Köppen é do tipo Aw, com estações seca (março a setembro) e chuvosa (outubro a abril) bem definidas, com temperaturas médias de 23,47; 23,38;

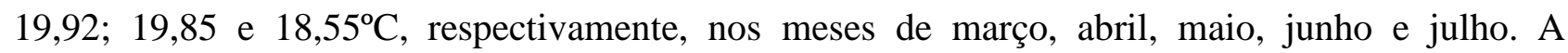
precipitação mensal durante o período experimental (março a julho de 2012) foi de 243,8; 181,7; 49,8; 52,3 e 3,1 mm, segundo dados coletados na Estação Meteorológica Convencional de Jataí, localizada no Campus Jatobá da Regional Jataí na Universidade Federal de Goiás.

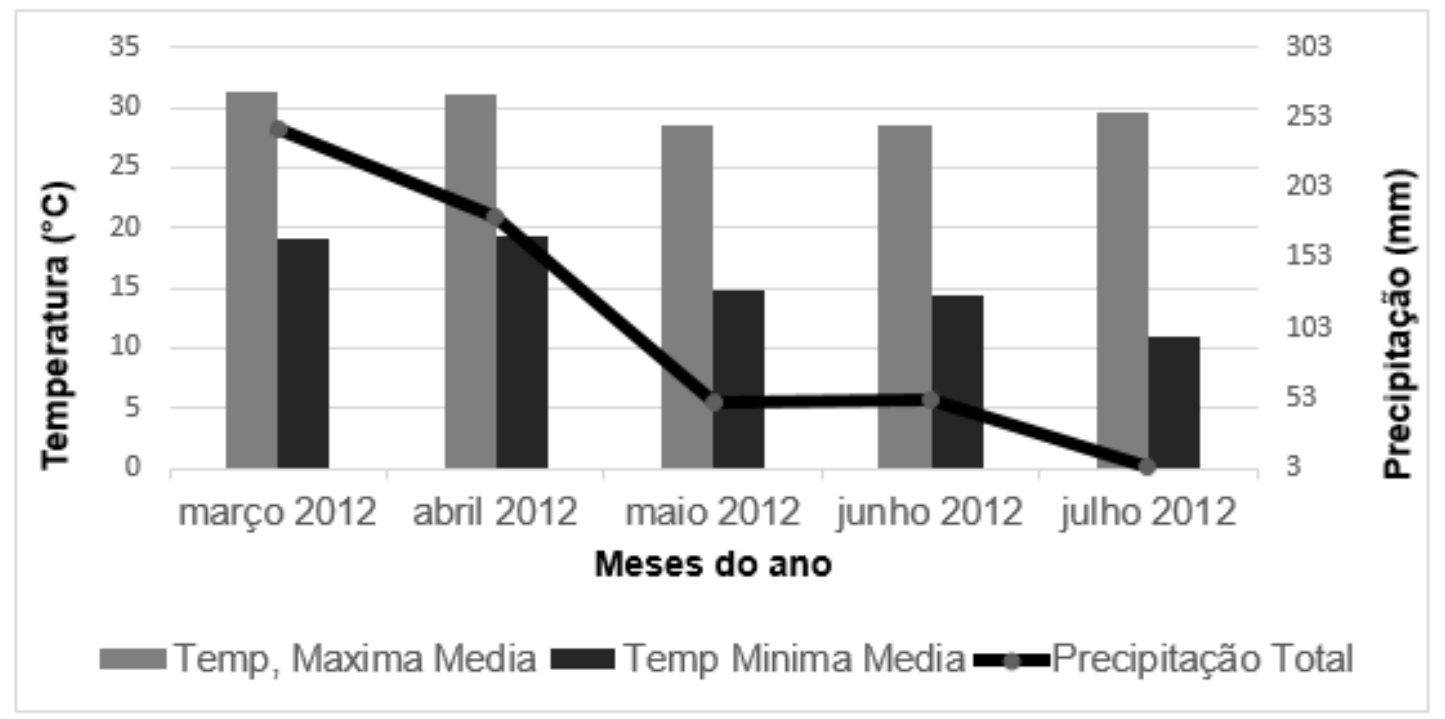

Figura 1. Temperatura $\left({ }^{\circ} \mathrm{C}\right)$ e precipitação média $(\mathrm{mm})$ observada durante o período março a julho de 2012 no Fazenda Experimental da UFG - Jataí.

O delineamento experimental adotado foi o de blocos ao acaso num arranjo fatorial $3 \mathrm{x} 2$, sendo os fatores três densidades de semeadura (10, 15 e $\left.20 \mathrm{~kg}^{\circ} \mathrm{ha}^{-1}\right)$ e duas alturas de cortes (50 ou $70 \mathrm{~cm}$ ), mantendo-se altura residual de $20 \mathrm{~cm}$, com seis repetições, totalizando 36 parcelas de 87,6 m² cada, numa área de 3140,8 $\mathrm{m}^{2}$.

Após 18 dias do plantio, foi realizado o controle de plantas daninhas com aplicação do herbicida 2,4D na diluição de 0,3/200 e usando $200 \mathrm{~L}$ calda/ha, aplicadas com bicicleta pulverizadora. 
O corte de uniformização foi realizado no dia 25 de abril de 2012, 41 dias após o plantio da cultura. Antes do corte de uniformização, foi realizada a avaliação da densidade de plantas, utilizando-se um quadrado de $1 \mathrm{~m}^{2}$ com quatro repetições por parcela, para a determinação da média do número de plantas do estande nos tratamentos.

O primeiro corte foi realizado à altura de $50 \mathrm{~cm}$ e aconteceu após 34 dias do corte de uniformização, ou seja, no dia 29 de maio de 2012, e o corte aos 70 cm após 52 dias, ou seja, em 16 de junho de 2012. O segundo corte de $50 \mathrm{~cm}$ aconteceu no dia 10 de julho, 42 dias após o primeiro.

Como o corte à $50 \mathrm{~cm}$ proporcionou duas coletas durante o período de avaliação e o corte à $70 \mathrm{~cm}$ apenas uma, optou-se por usar as referências de taxa de crescimento do milheto para as discussões.

Para se avaliar a produção de matéria natural (MN) e matéria seca (MS), foram coletadas amostras de uma área de $0,25 \mathrm{~m}^{2}$ a $20 \mathrm{~cm}$ de altura, medida com uma fita métrica, em quatro repetições/parcela. Para a realização dos cortes das áreas avaliativas foram utilizadas tesouras tipo poda de jardineiro e para a área total do dossel roçadeira costal, sendo o material cortado e retirado manualmente da área.

As amostras foram pesadas em balança analítica para a determinação da produção de MN e, posteriormente, foram colocadas em estufa de ventilação forçada a $65{ }^{\circ} \mathrm{C}$ por 72 horas para a determinação da matéria pré-seca e cálculo da produção por área de massa e dos nutrientes.

As avaliações de MS, proteína bruta (PB), fibra em detergente neutro corrigida para cinzas e proteína (FDNcp), fibra em detergente ácido (FDA), matéria mineral (MM) e extrato etéreo (EE) foram realizadas no Laboratório de Nutrição Animal da Universidade Federal de Goiás, conforme metodologia descrita por Silva \& Queiroz ${ }^{(9)}$.

Todas as análises estatísticas foram realizadas no programa SAS versão $9.2^{(10)}$ a $5 \%$ de probabilidade. Para a avaliação do número de plantas, foi considerado apenas o efeito da densidade de semeadura com delineamento em blocos ao acaso (DBC). Para avaliar as características do primeiro corte e do período total, os dados foram analisados em DBC considerando o fatorial 3x2 (densidade $\mathrm{x}$ altura) com o efeito de densidade na parcela e de altura de corte na subparcela. As médias foram comparadas pelo teste Tukey.

\section{Resultados e Discussão}

Não houve $(\mathrm{P}>0,05)$ interação entre densidade de semeadura e altura de corte em nenhum fator avaliado, o que possibilitou que esses fatores fossem estudados de forma independente. O número de plantas na densidade de semeadura de $20 \mathrm{~kg}$ ha-1 (Tabela 1) foi superior $(\mathrm{P}<0,05)$ quando comparado a de 10 kg.ha-1 (78,1 e 53,6 plantas/m², respectivamente). Já a densidade de 15 kg.ha-1 com 68,5 plantas $/ \mathrm{m}^{2}$ foi estatisticamente igual às demais densidades.

A densidade de $10 \mathrm{~kg} \cdot \mathrm{ha}^{-1}$ apresentou menor número de plantas por $\mathrm{m}^{2}$, com média de 53,6 plantas $/ \mathrm{m}^{2}$. No entanto, essa média foi superior à considerada ideal por Evangelista ${ }^{(11)}$, que recomenda 10 a 20 plantas $/ \mathrm{m}^{2}$ para a formação do estande adequado, demonstrando a capacidade do 
milheto para manter a população de plantas, garantir a cobertura do solo e formar relvado adequado para o pastejo.

Tabela 1. População de plantas de milheto safrinha em três densidades de semeadura

\begin{tabular}{|c|c|c|c|c|c|}
\hline \multirow{3}{*}{ Característica } & \multicolumn{4}{|c|}{ Densidade de semeadura (kg.ha- } & \multirow{3}{*}{ Valor-P ${ }^{1}$} \\
\hline & \multicolumn{3}{|c|}{ 1) } & \multirow[t]{2}{*}{ CV (\%) } & \\
\hline & 10 & 15 & 20 & & \\
\hline Número de plantas $\left(\mathrm{m}^{2}\right)$ & $53,6 b$ & $68,5 \mathrm{ab}$ & $78,1^{\mathrm{a}}$ & 29,5 & 0,0174 \\
\hline
\end{tabular}

Os fatores relacionados à produção do milheto em kg.ha-1 (Tabela 2) não apresentaram diferenças $(\mathrm{P}>0,05)$ quando avaliados nas diferentes densidades de semeadura. Isso pode ser justificado pela alta capacidade de perfilhamento do milheto mesmo em baixas densidades de semeadura, conseguindo, assim, equilibrar a produção de biomassa. Silva et al. ${ }^{(12)}$ também avaliaram a população de plantas de milheto e verificaram que a densidade de semeadura não influenciou na produção de biomassa. Domukoski et al. ${ }^{(3)}$ ressaltaram que outros estudos verificaram que a densidade de semeadura não exerce influência na produção de biomassa.

Tabela 2. Produção média de matéria seca (PMS), matéria natural (PMN), proteína bruta $(\mathrm{PB})$, fibra insolúvel em detergente neutro corrigidos para cinzas e proteína (PFDNcp), fibra insolúvel em detergente ácido (PFDA), matéria mineral (PMM) e extrato etéreo (PEE) do milheto em diferentes densidades de semeadura

\begin{tabular}{lcccccc}
\hline \multirow{2}{*}{$\begin{array}{c}\text { Característica } \\
\text { (kg.ha- }\end{array}$} & \multicolumn{3}{c}{ Densidade $\left(\mathbf{k g . h a}^{-\mathbf{1}}\right)$} & Média & $\begin{array}{c}\text { CV } \\
\mathbf{( \% )}\end{array}$ & Valor-P \\
\cline { 2 - 4 } & $\mathbf{1 0}$ & $\mathbf{1 5}$ & $\mathbf{2 0}$ & & \\
\hline PMS & 1486,44 & 1604,01 & 1545,45 & 1546,43 & 16,11 & 0,6592 \\
PMN & 8509,75 & 8881,16 & 8816,00 & 8668,97 & 16,67 & 0,6817 \\
PPB & 192,44 & 214,92 & 194,65 & 200,57 & 16,21 & 0,1590 \\
PFDNcp & 923,64 & 976,10 & 975,97 & 965,46 & 23,21 & 0,6141 \\
PFDA & 556,30 & 567,26 & 597,36 & 573,64 & 17,92 & 0,5390 \\
PMM & 117,57 & 124,22 & 125,88 & 122,55 & 18,21 & 0,5149 \\
PEE & 24,33 & 24,72 & 26,13 & 24,91 & 21,56 & 0,6781 \\
\hline
\end{tabular}

Avaliando a produtividade nas alturas de corte, houve maior PMS, PMN, PPB, PFDNcp, PFDA e PMM $(\mathrm{P}<0,05)$ na altura de corte de $70 \mathrm{~cm}$ quando considerado apenas o primeiro corte da altura de $50 \mathrm{~cm}$ (Tabela 3). 
Tabela 3. Produção de matéria seca (PMS), matéria natural (PMN), proteína bruta (PB), fibra em detergente neutro corrigidos para cinzas e proteína (PFDNcp), fibra em detergente ácido (PFDA), matéria mineral (PMM) e extrato etéreo (PEE) do milheto safrinha em diferentes alturas de corte

\begin{tabular}{|c|c|c|c|c|c|}
\hline \multirow{2}{*}{$\begin{array}{l}\text { Característica } \\
\left(\mathrm{kg} \mathrm{ha}^{-1}\right)\end{array}$} & \multicolumn{2}{|c|}{ Altura (cm) } & \multirow{2}{*}{ Média } & \multirow{2}{*}{ CV (\%) } & \multirow{2}{*}{ Valor-P } \\
\hline & 50 & 70 & & & \\
\hline PMS & 1246,85 & 1843,75 & - & 16,11 & 0,0001 \\
\hline PMN & 7812,33 & 9525,61 & - & 16,67 & 0,0256 \\
\hline PPB & 163,36 & 237,77 & - & 16,21 & 0,0001 \\
\hline PFDNcp & 742,06 & 1175,08 & - & 23,21 & $<0,0001$ \\
\hline PFDA & 431,79 & 715,49 & - & 17,92 & $<0,0001$ \\
\hline PMM & 106,00 & 139,11 & - & 18,21 & 0,0022 \\
\hline PEE & 23,15 & 26,97 & 24,91 & 21,56 & 0,3284 \\
\hline
\end{tabular}

Quando foram consideradas as taxas de acúmulo nos intervalos de 34 e 52 dias, respectivamente, para as alturas de 50 e $70 \mathrm{~cm}$, observaram-se valores de 36,67 e 35,46 kg/ha.dia ${ }^{-1}$ PMS; 229,77 e 183,18 kg/ha.dia-1 PMN; 4,80 e 4,57 kg/ha.dia ${ }^{-1}$ PPB; 21,82 e 22,60 kg/ha.dia-1 PFDNcp; 12,70 e 13,76 kg/ha.dia ${ }^{-1}$ PFDA; 3,11 e 2,67 kg/ha.dia ${ }^{-1}$ PMM; 0,68 e 0,52 kg/ha.dia ${ }^{-1}$ PEE. Esses valores revelaram maior eficiência quantitativa em produção de massa, proteína, minerais e extrato etéreo da planta à altura de $50 \mathrm{~cm}$. Apesar de os valores serem inferiores aos observados na literatura ${ }^{(13-15)}$, deve ser considerado o fato de a cultura ter sido avaliada na entressafra em condições de temperatura e precipitação restritivas.

Estas observações estão de acordo com Pereira et al. ${ }^{(16)}$, quando afirmam que o tempo necessário para atingir determinado estádio fenológico é controlado pelas temperaturas médias diárias do ambiente, caso não haja falta de água, sendo decisivo na duração do ciclo da cultura. No entanto, contrariam as observações de Payne ${ }^{(17)}$, que diz que quando semeado após culturas de verão, o milheto apresenta elevada tolerância a períodos com déficit hídrico.

A altura de manejo de $50 \mathrm{~cm}$ proporcionou dois cortes, durante o período experimental, já na altura de $70 \mathrm{~cm}$ foi possível fazer apenas um corte, fator que pode ser associado à redução da precipitação e à temperatura, pois no mês de junho, quando ocorreu o corte da altura de $70 \mathrm{~cm}$, a precipitação foi inferior a 2,0 mm, enquanto que a temperatura atingiu valores mínimos de $14,4{ }^{\circ} \mathrm{C}$. Além disso, a menor capacidade de rebrota pode ser, também, associada à redução do fotoperíodo no pós-corte, que ocorreu já no inverno.

Estes fatos estão de acordo com Lemos et al. ${ }^{(18)}$, que avaliaram épocas de semeadura do milheto em sucessão a soja e observaram influência da menor disponibilidade hídrica no desenvolvimento vegetativo da cultura. Da mesma forma, Nirval et al. ${ }^{(19)}$ afirmaram que a produção e a composição química da matéria seca do milheto são alteradas pela época de semeadura.

Assim, em virtude de fatores relacionados com o meio ambiente ou com o genótipo, ocorrem variações nas características de crescimento e no comportamento fisiológico do milheto. Esses aspectos, quando em equilíbrio, colaboram para maximizar o aproveitamento do potencial dessa 
forrageira, em condições de pastejo ${ }^{(20)}$.

Não foi observado efeito da densidade de semeadura $(\mathrm{P}>0,05)$ na produção do milheto no período total (Tabela 4). Esse fator já era esperado, uma vez que, quando medida a produção em apenas um corte de cada altura, foi observada similaridade de produção entre as duas densidades.

Tabela 4. Produção média de matéria seca (PMS), matéria natural (PMN), proteína bruta (PB), fibra em detergente neutro corrigido para cinza e proteína (PFDNcp), fibra em detergente ácido (PFDA), matéria mineral (PMM) e extrato etéreo (PEE) do milheto safrinha em diferentes densidades de semeadura no período total

\begin{tabular}{lcccccc}
\hline $\begin{array}{l}\text { Característica } \\
\text { (kg.ha- }\end{array}$ & \multicolumn{3}{c}{ Densidade $\left(\mathbf{k g . h a}^{-\mathbf{1}} \mathbf{)}\right.$} & \multirow{2}{*}{ Média } & $\begin{array}{c}\text { CV } \\
\mathbf{( \% )}\end{array}$ & Valor-P \\
\cline { 2 - 4 } & $\mathbf{1 0}$ & $\mathbf{1 5}$ & $\mathbf{2 0}$ & & $\mathbf{1}$ & \\
\hline PMS & 1812,77 & 1869,21 & 1862,82 & 1848,27 & 15,46 & 0,8411 \\
PMN & 10012,17 & 10451,67 & 10086,58 & 10183,47 & 15,16 & 0,5901 \\
PPB & 230,12 & 255,03 & 232,01 & 239,05 & 15,44 & 0,1560 \\
PFDNcp & 1118,30 & 1165,94 & 1171,16 & 1153,36 & 28,66 & 0,6328 \\
PFDA & 671,69 & 686,09 & 709,75 & 689,18 & 16,06 & 0,6004 \\
PMM & 140,73 & 148,25 & 147,93 & 145,64 & 16,25 & 0,5489 \\
PEE & 29,72 & 30,92 & 32,89 & 31,18 & 22,58 & 0,4574 \\
\hline
\end{tabular}

O segundo corte da altura de $50 \mathrm{~cm}$ apresentou redução de $50 \%$ da produção de massa, o que diminuiria a oferta forrageira na seca, corroborando a afirmação de Kollet et al. ${ }^{(21)}$, ao avaliarem rendimento forrageiro, de que na rebrota a produtividade diminui.

Em função disso, não houve efeito da altura de corte $(\mathrm{P}>0,05)$ na produção do milheto no período total (Tabela 5), demonstrando que, mesmo com dois cortes, a produção da altura de $50 \mathrm{~cm}$ foi semelhante à produção de apenas um corte aos $70 \mathrm{~cm}$. O segundo corte apresentou menor produção comparado ao primeiro, principalmente devido à diminuição da precipitação pluviométrica, do fotoperíodo e a menor temperatura mínima nos meses finais do experimento, diminuindo consequentemente a oferta de forragem na rebrota, corroborando Kollet et al. ${ }^{(21)}$, que afirmam que a produção do milheto diminui na rebrota. Além das restrições das condições bióticas para o crescimento, há a resposta fenológica da cultura às mesmas, que resultam na paralisação do crescimento para a emissão da haste floral ${ }^{(13)}$.

Pena et al. ${ }^{(22)}$ ressaltaram a importância da frequência dos cortes para controlar o alongamento de colmos, as frações indesejáveis da planta (ocorrem em maior percentual em plantas mais altas e mais velhas), o teor de FDA, o aumento do período para rebrota e o valor nutritivo, tornando indiferente o aumento da produção de MS total no final do período. No entanto, no período total em que este experimento foi conduzido, não foram observadas diferenças em PPB, PFDN ou PFDA nas diferentes alturas de corte. 
Tabela 5. Produção de matéria seca (PMS), matéria natural (PMN), proteína bruta (PB), fibra em detergente neutro corrigido para cinza e proteína (PFDNcp), fibra em detergente ácido (PFDA), matéria mineral (PMM) e extrato etéreo (PEE) do milheto safrinha em diferentes alturas de corte no período total

\begin{tabular}{|c|c|c|c|c|c|}
\hline \multirow{2}{*}{$\begin{array}{l}\text { Característica } \\
\left(\mathrm{kg} \mathrm{ha}^{-1}\right)\end{array}$} & \multicolumn{2}{|c|}{ Altura (cm) } & \multirow{2}{*}{ Média } & \multirow{2}{*}{ CV (\%) } & \multirow{2}{*}{ Valor-P } \\
\hline & 50 & 70 & & & \\
\hline PMS & 1852,78 & 1843,76 & 1848,27 & 15,46 & 0,9588 \\
\hline $\mathrm{PMN}$ & 10841,33 & 9525,61 & 10183,47 & 15,16 & 0,1130 \\
\hline PPB & 240,33 & 237,78 & 239,05 & 15,44 & 0,9022 \\
\hline PFDNcp & 1128,53 & 1175,08 & 1153,36 & 28,66 & 0,6886 \\
\hline PFDA & 662,86 & 715,49 & 689,18 & 16,06 & 0,4072 \\
\hline PMM & 152,17 & 139,11 & 145,64 & 16,25 & 0,3192 \\
\hline PEE & 32,89 & 29,47 & 31,18 & 22,58 & 0,5169 \\
\hline
\end{tabular}

\section{Conclusão}

As densidades de semeadura não tiveram efeito sobre a produção do milheto, sendo a utilização da menor quantidade de sementes um fator importante na redução do custo de implantação da cultura. No presente experimento, $10 \mathrm{~kg} /$ ha de semente foram suficientes para se obter uma densidade de plantas acima do recomendado.

Em condições de limitação hídrica, de temperatura e de fotoperíodo, como os observados neste experimento, não foi possível realizar mais que dois cortes e, por proporcionar maior período de utilização da pastagem ou dois pastejos, recomenda-se manejar o milheto na altura de corte de 50 cm ou fazer o plantio antes do mês de março.

\section{Referências}

1. Pires FR, Assis RL, Silva GP, Braz AJBP, Santos SC, Vieira Neto SA, et al. Desempenho agronômico de variedades de milheto em razão da fenologia em pré-safra. Biosci J. 2007; 23(3): 41-9.

2. Bergamaschine AF, Freitas RVL, Valério Filho WV. Substituição do milho e farelo de algodão pelo milheto no concentrado da dieta de novilhos em confinamento. Rev Bras Zootec. 2011; 40(1): 154-9.

3. Domukoski JF, Costa ACT, Lázaro RL. Produção de biomassa do milheto em função do espaçamento entrelinhas e da densidade de semeadura. Scientia Agraria Paranaensis. 2014; 13(2): 152-60.

4. Costa ACT, Geraldo J, Pereira MB. Unidades térmicas e produtividade em genótipos de milheto semeados em duas épocas. Pesq Agrop. 2005; 40(12): 1171-7. 
5. Rodrigues PB, Rostagno HS, Albino LFT, Gomes PC, Barboza WA, Santana RT. Valores energéticos do milheto, do milho e subprodutos do milho, determinados com frangos de corte e galos adultos. Rev Bras Zootec. 2001; 30: 1767-78.

6. Pereira Filho IA, Ferreira AS, Coelho, AM, Casela, CR, Karam, D, Rodrigues, JAS, et al. Manejo da cultura do milheto. Circular Técnica 29 [Internet]. 2003 [acesso em 2017 abr 28]; 17p. Disponível em: https://www.infoteca.cnptia.embrapa.br/bitstream/doc/487545/1/Circ29.pdf

7. Martins Netto DA, Durães FOM. Milheto tecnologias de produção e agronegócio. [Internet]. 2005 [acesso em 2017 abr 28]; 205p. Disponível em: http://livimagens.sct.embrapa.br/amostras/00076930.pdf

8. Empresa Brasileira de Pesquisa Agropecuária (BR). Sistema brasileiro de classificação de solos. Rio de Janeiro: Centro Nacional de Pesquisa de Solos/EMBRAPA Produção de Informação [Internet]. 2006 [acesso em 2017 abr 28]; Disponível em: http://www.agrolink.com.br/downloads/sistema-brasileiro-de-classificacaodos-solos2006.pdf

9. Silva DJ, Queiroz AC. Análise de alimentos: Métodos químicos e biológicos. 3.ed. Viçosa: UFV; 2002.

10. SAS. Statistical Analysis System Institute. SAS user’s guide. Statistic. Cary, NC: SAS Institute INC; 2008.

11. Evangelista AR. Formação e manejo de pastagens tropicais. Apoio ao Produtor Rural. Coordenadoria de Extensão. Circular Técnica [Internet]. 1995. [acesso em 2017 abr 28]; 35p. Disponível em: http://www.editora.ufla.br/index.php/boletins-tecnicos-e-de-extensao/boletins-de-extensao

12. Silva NB, Silva AC, Costa ACT, Pimentel C. Efeito da população de plantas na produção de biomassa e de grãos de milheto pérola, “cultivar ENA 1”, semeado na época da seca. Ver Univ Rural. 2004; 24: 57-62.

13. Roman J, Rocha MG da, Genro TCM, Santos DT dos I, Freitas FK de, Montagner DB. Características produtivas e estruturais do milheto e sua relação com o ganho de peso de bezerras sob suplementação alimentar. Rev Bras Zootec. 2008; 37(2): 20511.

14. Pacheco RF, Alves Filho DC, Brondani IL, Nornbergii JL, Pizzutii LAD, Callegaro ÁM. Características produtivas de pastagens de milheto ou capim sudão submetidas ao pastejo contínuo de vacas para abate. Cienc Anim Bras. 2014; 15(3): 266-76.

15. Costa e Silva MP, Basto D de C, França AF de S, Alves BG, Melo AHF de, Jacovetti R, et al. Taxa de acúmulo de forragem de três cultivares de milheto sob alturas pré-corte. In: Anais do $25^{\circ}$ Congresso Brasileiro de Zootecnia - ZOOTEC 2015, 2015; Fortaleza. Fortaleza - CE: IFCeará; 2015. CD Rom.

16. Pereira AR, Angelocci LR, Sentelhas PC. Agrometeorologia, fundamentos e aplicações práticas. Guaíba: Agropecuária [Internet]. 2002 [acesso em 2017 abr 28]; Disponível em: http://www.ebah.com.br/content/ABAAAAU8sAA/apostila-agrometeorologia

17. Payne WA. Optimizing crop water use in sparse stands of pearl millet. Crop Sci. 2000; 92: 808-14.

18. Lemos LB, Nakagawa J, Crusciol CA, Junior WC, Silva TRB. Influência da época de semeadura e do manejo da parte aérea de milheto sobre a soja em sucessão em plantio direto. Bragantia. 2003; 62(3): 405415.

19. Nirval BG, Chavan AA, Shinde JS, Gore SB. Management of sowing date of rainy-season crops for sustainable crop yield under dryland condition. Indian J Agric Sci. 1995; 65(3): 170-4.

20. Guideli C, Favoretto V, Malheiros EB. Produção e qualidade do milheto semeado em duas épocas e adubado com nitrogênio. Pesq Agrop. 2000; 35(10): 2093-8.

21. Kollet JL, Diogo JMS, Leite GG. Rendimento forrageiro e composição bromatológica de variedades de 
milheto (Pennisetum glaucum (L.) R. BR.). Rev Bras Zootec. 2006; 35(4): 1308-15.

22. Pena KS, Nascimento Junior D, Silva SC, Euclides VPB, Zanine AM. Características morfogênicas, estruturais e acúmulo de forragem do capim-tanzânia submetido a duas alturas e três intervalos de corte. Rev Bras Zootec. 2009; 38(11): 2127-36. 